\title{
People with dementia playing casual games on a tablet
}

\author{
Article \\ Published Version
}

Groenewoud, H., de Lange, J., Schikhof, Y., Astell, A., Joddrell, P. and Goumans, M. (2017) People with dementia playing casual games on a tablet. Gerontechnology, 16 (1). pp. 37-47. ISSN 1569-111X Available at https://centaur.reading.ac.uk/75404/

It is advisable to refer to the publisher's version if you intend to cite from the work. See Guidance on citing.

Publisher: International Society for Gerontechnology

All outputs in CentAUR are protected by Intellectual Property Rights law, including copyright law. Copyright and IPR is retained by the creators or other copyright holders. Terms and conditions for use of this material are defined in the End User Agreement.

\section{www.reading.ac.uk/centaur}

\section{CentAUR}

Central Archive at the University of Reading

Reading's research outputs online 


\title{
Original
}

\section{People with dementia playing casual games on a tablet}

\author{
Hanny Groenewoud MD PhD ${ }^{\mathrm{a}, *}$ \\ Jacomine de Lange $\mathrm{PhD}^{\mathrm{a}}$ \\ Yvonne Schikhof ${ }^{a}$ \\ Arlene Astell $\mathrm{PhD}^{\mathrm{b}, \mathrm{c}}$ \\ Phil Joddrell ${ }^{b}$ \\ Marleen Goumans PhDa
}

\begin{abstract}
a Rotterdam University of Applied Sciences, Research Centre Innovations in Care, Rotterdam, The Netherlands, 'b School of Health and Related Research, University of Sheffield, Sheffield, UK, ' Ontario Shores Centre for Mental Health Sciences, Whitby, Ontario, Canada; *Corresponding author: j.h.groenewoud@hr.nl
\end{abstract}

\begin{abstract}
H. Groenewoud, J. de Lange, Y. Schikhof, A. Astell, P. Joddrell, M. Goumans. Experiences of people with dementia playing causal games on a tablet. Gerontechnology 2017; 16(1):37-47; doi:10.4017/gt.2017.16.1.004.00 Objective Preserving clients' quality of life (QoL) has become increasingly important in dementia care. Engagement in pleasant and meaningful activities may influence this QoL. We studied people with dementia's experiences and views of independent tablet games in a practice-based study, conducted at two day-care centres and five small-scale living facilities for people with dementia in the city of Rotterdam. Methods The participants were 54 clients ( 24 men, 30 women; mean age 83 years) who participated in a total of 177 game-playing sessions. Ten existing iPad games and three new game prototypes were evaluated. Written informed consent was obtained from the clients or the clients' representatives prior to the study. Data collection included epidemiological and game playing characteristics. Observers took note of the specific game(s) offered, the clients' mood and engagement, and the duration of game playing. Immediately after each participant finished playing, a short 4-question interview was conducted to discover their opinion on the game. The participants' answers were recorded verbatim. Qualitative content analysis was used to explore their experiences and views of the games. Results This study revealed positive experiences related to people's need for achievement, self-esteem, sense of connection and belonging, identity, having something to do, and admiration for the game. Negative experiences included failure (low self-esteem), annoyance and a sense of insecurity. Conclusions This study shows there is potential for people with dementia to play casual games on a tablet as a pleasant and meaningful activity. It is important, however that there is a match between the game, the touchscreen skills of the person with dementia, and their ambitions or interests. It is challenging to find the right game for the right person. An interactive tool to support the choice of the game that is most suitable and a database of dementia-friendly tablet games may support the use of these games by people with dementia, in health care organisations as well as at home.
\end{abstract}

Keywords: dementia, casual game, tablet, experience

Preserving clients' quality of life (QoL) has become increasingly important in dementia care. Mood, engagement in pleasant activities, and the ability to perform activities of daily living (ADLs) are important factors that influence the QoL of people with dementia ${ }^{1}$. Recent studies among residents of long-term care facilities who are living with dementia, confirm that activity involvement is beneficial for their $\mathrm{QoL}^{2,3}$.

One of the quality statements in the UK NICE quality standard 'Dementia: independence and wellbeing' states that people with dementia should be enabled to take part in leisure activities of their interest and choice ${ }^{4}$. Dutch dementia care professionals acknowledge that people with dementia have a wide range of different interests and preferences for taking part in leisure activities $^{5}$. Professionals are willing to offer varying activities to people with dementia. However, due to lack of time and resources, they frequently feel themselves constrained to offer standard group activities rather than one-to-one activities. One of the dementia care professionals involved 
in the stage of problem definition for the current study, said: "Some people experience overstimulation during group activities. They have little opportunity for pleasant experiences for themselves". According to another care professional, "there are a lot of group activities, also involving technology [...], but there is an increasing number of people who prefer to do something alone rather than to participate in a group activity or attend a day-care centre". Thus, there is a growing need for solo, independent activities for clients who prefer not to participate in groups.

In recent years, playing videogames has been shown to have psychosocial benefits notably in motivational, emotional and social domains ${ }^{6}$. Additionally, touchscreen technologies are making these games accessible to a wide range of people, including those living with dementia ${ }^{7}$. Recent studies concerned the use of an interactive touchscreen system containing a large database of media to elicit reminiscence and support conversation between people with dementia and caregivers $^{8-10}$. A similar hypermedia system, with three virtual reality environments and a wide range of virtual activities to be used by the person with dementia alone, was then developed and tested by Alm et al. ${ }^{11,12}$. As touchscreen devices are relatively simple to operate and mobile tablet computers such as the Apple iPad can be used anywhere, there is potential for virtual games and activities to provide pleasant and meaningful solo activity in dementia care.

The Apple iPad was first introduced in 2010 with apps, including games, being made available through the iTunes store, the online digital media store operated by Apple Inc. In 2011, the InTouch project started to explore the application of iPad casual games for people with dementia. One of the aims of InTouch was to gain insight in how people with dementia feel about playing one-player casual games and how to make these games available to people with dementia.

To achieve these aims, the InTouch project comprised three practice-based sub-studies. The first sub-study (2011) looked at the best way to present the tablet to people with dementia who typically were not experienced computer users. This led to the development of a bespoke dementiafriendly case for the iPad that is firm and balanced on a table, but also comfortable for placing on the lap and made of a durable, wipeable material ${ }^{13}$ (Figure 1). In a second sub-study (20112012), the prerequisites for the design of tablet games for people with dementia were investigated by means of a literature study ${ }^{14}$. The third sub-study (2012-2014) was designed to look at the impact of independently playing iPad games on the wellbeing and behaviour of people with dementia, and to study the factors that influence the use of one-player iPad games in dementia care. This article is based on the third sub-study and focuses on the experiences and views of the iPad games by people with dementia.

\section{Methods \\ Design}

This study used a mixed-method design. Quantitative data were collected in relation to frequency and duration of game play. Qualitative data included observations and interviews conducted at the end of each session.

\section{Setting and participants}

This practice-based research was conducted at two day-care centres for people with dementia and five small-scale living facilities from three health care organizations (Laurens, Aafje and Humanitas) in the city of Rotterdam, The Netherlands.

The study group consisted of 54 clients: 24 men (mean age: 83.5, SD: 6.6, range: 59.290.6) and 30 women (mean age: 83.5 , SD: 5.3, range 71.5-94.8). The participants had all been diagnosed with dementia and were potentially interested in playing solo games on a tablet, according to healthcare staff at their institution, in particular nursing staff and a psychologist. Exclusion criteria were serious physical conditions that may hinder game playing on a tablet, including severe visual impairment, physical disability to handle the tablet in its special cover, and severe apraxia. Health care staff who saw the clients on a regular basis determined which clients were eligible. The eligible clients and their representatives received written information on the project. Written informed consent was obtained from the clients and from the clients' representatives in cases where the client was deemed not capa-

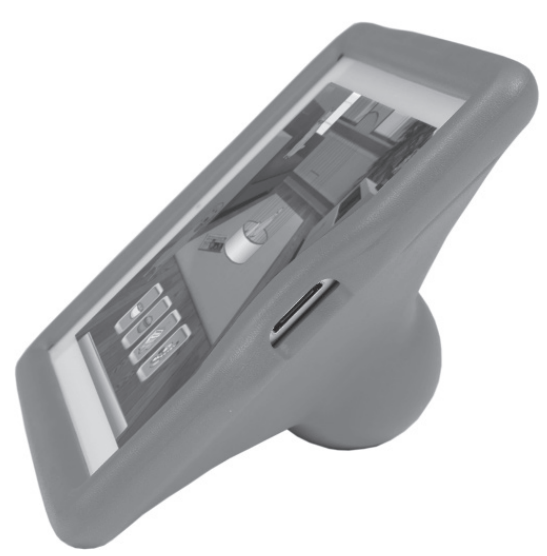

Figure 1. The 'Proud to play' iPad case 
ble to give informed consent. In addition, prior to each session the clients were asked again whether they were willing to play a game and to answer some questions for the study.

\section{Games}

Ten existing iPad games and three new game prototypes were evaluated (Table 1). The existing games included:

-Four traditional board and card games for the iPad (Shuffleboard or iSjoel, Checkers or Draughts, Dominoes, and Solitaire);

-One musical instrument app (Xylophone);

-Three interactive visual or sound apps (Tesla Toy, Line Art and Soundrop);

-One virtual fish pond (Fish Pond);

-One virtual pet (Talking Tom).

These games were selected in consultation with an experienced dementia care unit head nurse from a list of apps that have potential for trying with people with dementia, drawn up by two of the authors (YS and AA) (Research Centre Innovations in Care, n.d., unpublished internal document). The selected games vary in complexity.

Three other, new game prototypes were specifically designed for people with dementia. The development of these three games (Shopping, Pets and Soccer) is described elsewhere ${ }^{14}$. The game themes were based on interviews by students with people with dementia about their preferences for leisure activities. To support clients with cognitive impairment to initiate or maintain playing, attention was paid to include visual and auditory cues in the new game prototypes, as recommended by Alm et al. ${ }^{11,12}$.

An iPad containing the selected games was provided for each of the three health care organizations. The iPads were protected by a lightweight cover, 'Proud to Play', that had been developed in the first stage of the project ${ }^{13}$ (Figure 1). The cover allows the iPad to stand in portrait or landscape mode on any flat surface, or to be laid on the client's lap. The on-off switch and volume control switch are covered in order to prevent unnecessary confusion for the clients during game play.

\section{Gaming observation sessions}

Each participant was invited to play a game on three different occasions. We sought to offer a different game on each of the three occasions. There was a guideline to support a uniform approach of the participants and choice of the game(s) to be played (Research Centre Innovations in Care, 2012, unpublished internal document). The start time of the observation was arranged with the nursing-assistants at the facility.
When this was deemed appropriate, the participant was informed only shortly before their gaming session that they were about to play a game. The choice of games offered reflected the participant's preferences as much as possible, using simple questions. If the participant would like two or more games, a choice between at most two of these games was offered. It was left up to the observer how the apps were offered, either verbally, by pointing at the icons or by showing pictures of the games. The new game prototypes became available only halfway the study and were included from that moment on. Most of the observations took place in a shared social space in the facility, with other residents or clients being present in the room. In some instances, participants were invited to go into a separate room to play.

A team of 12 observers were trained to collect data during the game play sessions. The observers were fourth-year students in nursing and occupational therapy of Rotterdam University of Applied Sciences, who were trained in observing people with dementia. Students were assigned to one of the three participating organisations, working in groups of two or three. An observation protocol and observation forms were used.

Observations started 15 minutes before inviting the client to play the tablet game and ended 15 minutes after the client finished playing. The observer was positioned at some distance from the participant with good view of the participant's face and posture. A second observer was used for part of the observations. This second observer was seated next to the participant to observe their interaction with the touchscreen. The observers were instructed to react friendly but neutral if the participant sought contact, and to intervene in case of problems with the app or the device. The second observer also conducted the interview at the end of the playing session.

\section{Procedure}

Background characteristics of the participants included age and gender, former profession, previous computer experience, and performance of activities in daily living using the 10-item Barthel Index ${ }^{15}$. Cognitive functioning was assessed by nursing staff and classified as mild, moderate, moderately severe or severe dementia, according to a brief clinical description of these stages ${ }^{16}$. Formal cognitive testing, using the Mini Mental State Examination (MMSE) ${ }^{17}$ or a similar tool, was not undertaken due to objections from two of the three participating organisations who considered such testing too challenging and burdensome for their clients. 


\section{Dementia and gaming}

Table 1. Game characteristics

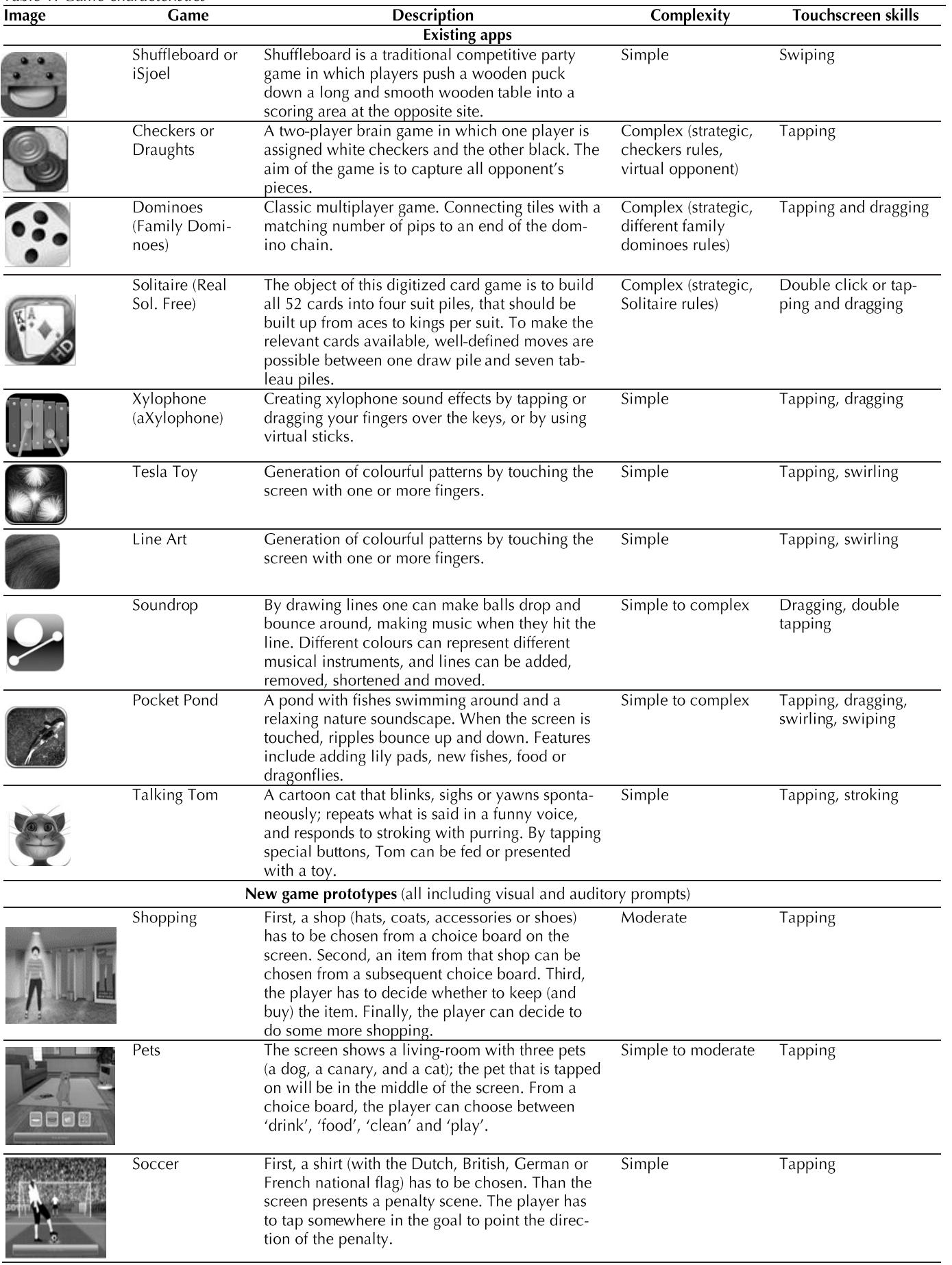


The observers took note of the specific game(s) offered, the start and end time of the observation session, and the start and end time of the game playing. The maximum duration of game play was set at 30 minutes; there was no minimum. Immediately after the participant finished playing, a short 4-question interview was conducted to discover their opinion on the game. The questions were: "Did you like the game?", "What did you like (or not like)?", "Would you like to play the game again someday?", and "How would you grade the game on a scale from 1 to 10 ?". The participant's answers were written down as accurately as possible. In their field notes, the observers recorded how each participant interacted with the game, specific behaviours (like reminiscing), and the occurrence and nature of any (social) interaction that took place with other clients or caregivers.

\section{Data analysis}

\section{Quantitative data}

Simple descriptive statistics were used to analyse the quantitative data, including frequencies and means. Data on the duration of game play were entered into Statistical Package for Social Sciences (SPSS), version 21, together with scores for the residents' mood and engagement (which are reported elsewhere)

\section{Qualitative data}

For the current publication, qualitative content analysis of the post-game interviews and the field notes are presented. These were transcribed and analysed using Atlas.ti 6.2. First, 'open coding' codes were applied to text fragments independently by two authors ${ }^{18}$, identifying all statements that reflected positive or negative reactions to iPad gaming. Discrepancies in coding and interpretation were discussed. Using 'axial coding', the open codes were then grouped into higher order categories which reflected the feelings and meaning of game playing as expressed by the participants.

\section{Ethical aspects}

The Medical Ethics Board of Erasmus MC, University Medical Center Rotterdam, granted an exemption from WMO-review [WMO = Wet medisch-wetenschappelijk onderzoek met mensen; Medical Research Involving Human Subjects Act]. All reported data were anonymized, so that individual persons could not be identified. In addition, local ethical protocols and guidelines of the participating healthcare organizations were respected, as well as the "Ethical code for evaluation of unwillingness in scientific research in legally incompetent (psycho)geriatric patients"19.

\section{Results}

In total, 177 observation sessions took place with the 54 clients with a dementia diagnosis. The majority of these clients (88\%) had no previous computer experience. According to health care staff, 23 participants had (moderately) severe dementia and 31 clients had mild to moderate dementia. Most observations took place in the main room of the facility, and sometimes in the client's bedroom or in a separate room.

Of the 177 observation sessions, 160 (90\%) included a game being played. In the other 17 sessions, the client did not play. This involved 13 clients, of whom 4 clients did not play at both the second and the third occasion. Reasons for not playing were negative recollections of the first session, being busy doing something else or just not being in the mood. Mean playing time was 20.9 \pm 8.9 minutes (range: $2-30$ ), with 66 (41\%) of the 160 playing sessions lasting 30 minutes or more. Participants whose dementia was described as mild to moderate played for a longer time (mean: $23.6 \pm 8.2$ minutes; range: $5-30$ ) than participants whose dementia was identified as (moderately) severe (mean: $16.8 \pm 8.3$ minutes; range: $2-30$ ). In $54 \%$ of the total sessions played by the participants with mild to moderate dementia, the duration of game play was up to 30 minutes; for clients with (moderately) severe dementia, this was $17 \%$.

The game most frequently chosen was shuffleboard, being played in 82 observation sessions. This was followed by Talking Tom (29 sessions) and checkers ( 21 sessions). The three new games were each played on 15 to 19 occasions.

\section{Content analysis}

\section{Positive reactions}

When interviewed at the end of each session, the clients regularly spoke positively about the game. Their positive experiences were related to the following six themes: need for achievement, self-esteem, sense of connection and belonging, identity, having something to do, and admiration for the game.

Need for achievement. Some clients tended to seek challenges and rewards for success. This was often expressed as the ambition to gain higher scores, especially in the more competitive games, like iSjoel.

"I like the score counting. I want to reach higher scores". (F5, male, 85 years, mild dementia, daycare centre; game: iSjoel)

"I like it to gain points. That's me, I want points". (E2, male, 87 years, mild dementia, small-scale living facility; game: iSjoel)

Other clients saw the games as an intellectual 
challenge. They appreciated the fact that they had to use their brains when playing the game or that playing offered the opportunity to learn something.

Researcher: "What did you like about iSjoel?"

Client: "How it goes. You have to use your brains, of course. It is like playing with cards".

Researcher: "Would you like to play the game again someday?"

Client: "Yes. Because your brain will develop well". (A8, male, 82 years, mild dementia, day-care centre)

Researcher: "Would you like to play the game again someday?"

Client: "Oh yeah, that will be fine. If I have the time. I am doing it to learn something new, to benefit from it."

(B3, female, 85 years, moderate dementia, smallscale living facility; games: Talking Tom, Tesla Toy)

Higher self-esteem. On some occasions, playing a game on the tablet contributed to the client's self-esteem. These clients said that they had played well and that they were satisfied with the progress of the game.

"It's a nice sport, isn't it? It's nice, playing soccer. A real man thing, but I can do it too. A goal was scored every time". (A3, female, 84 years, mild dementia, day-care centre; game: Soccer)

"They all come in front and I play them all into the highest number. Then they say I'm good at it". (A3, female, 84 years, mild dementia, daycare centre; game: iSjoel)

Client: "I used to do it a lot, this game. [...] You need brains for this".

Researcher: "You did rather well".

Client (smiling): "Yes, indeed!".

(F4, male, 87 years, moderate dementia, daycare centre; game: Solitaire)

Sense of connection and belonging. Some clients experienced game play as a sociable experience; and explicitly referred to the interaction with the game.

"[Laughing:] It's so baffling. The whole thing is nice, especially that it's talking back". (B5, female, 91 years, moderate dementia, small-scale living facility; game: Talking Tom)

Sometimes, they related the game's theme to similar situations in their own lives.

"I do like it. My daughter has a dog too. I always feed it and it has to be walked too. Nice!" (A3, female, 84 years, moderate dementia, day-care centre; game: Pets)

Sense of identity. For some clients, the game brought back memories. Clients spoke about them having played the game when they were younger. Playing the game felt familiar to them.

"Solitaire, yes, I am used to play that. I play it on the computer at home occasionally". (A8, male, 82 years, mild dementia, day-care centre)

"It was nice, because I used to be a football goalkeeper myself". (B7, male, 90 years, moderate dementia, small-scale living facility; game: Soccer)

Having something to do. Playing a game on the iPad could also be appriciated just for being something to spend time on. Some clients mentioned that there was not always something to do, and that iPad gaming was a welcome recreation. For others, iPad gaming was not just something to do, but valued as a useful or meaningful activity.

"We sit and peer all day. It is nice to have something to do. And it is intelligent. It is a nice therapy". (B2, female, 91 years, moderate dementia, small-scale living facility; games: iSjoel and Dominoes)

"Pleasant game. Nice game. If you don't have anything to do, you can take a game like this. Then you spend time doing something. But you need money to buy stuff". (F9, female, 80 years, moderately severe dementia, day-care centre; game: Shopping)

Admiration for the game. To the question what they thought about the game, some clients answered that the game was beautiful or very special. Their admiration often concerned the non-familiar games, like Tesla Toy or Line Art:

"Yeah, beautiful. How do they make that? Very refined, very ingenious. Nice, a starry sky appears out of nothing, wonderful game. [...] I like the shapes, the rhythmic moves, the different colors. The thing is very spontaneous too, it's doing what it wants to do". ( $F 1$, male, 85 years, moderate dementia, day-care centre; game: Tesla Toy)

"Nice. Look at its head. Isn't it wonderful? It has a big mouth, though, saying everything what I say. Yeah, that's nice". (F8, female, 81 years, moderately severe dementia, day-care centre; game: Talking Tom)

\section{Negative experiences}

Playing games may also lead to low self-esteem, annoyance, or a sense of insecurity. Such negative experiences appeared to result from a mismatch between the game and the clients' skills, ambitions or interests.

Failure, low self-esteem. Sometimes, the game lowered the client's self-esteem. Feelings of failure were associated with the perception of the game, or the gaming situation, as too difficult. Feelings of failure were even stronger when clients realised that they were not able to play the game anymore:

"I did not like the effort. I used to be able to do this". (B1, female, 83 years, moderate dementia, small-scale living facility; game: Checkers) 


\section{Dementia and gaming}

Annoyance. Feelings of annoyance were expressed when the game did not meet the client's expectations. In these cases, the game was critiqued rather than the negative emotions being directed towards the clients themselves. Some of the games were different to what the client expected.

"No fun at all, because I had no opponent". (C1, male, 81 years, moderately severe dementia, small-scale living facility; game: iSjoel)

Clients could be annoyed by unfamiliar game rules, as was the case with Checkers. A client noted that 'it was against the rules' because the pieces could not be moved backwards:

"It didn't go very well. [...] You could not jump backwards and the board didn't cover the whole board". (A8, male, 82 years, mild dementia, daycare centre; game: Checkers)

In other cases, the game did not meet the client's ambitions. The game was considered too childish, or not challenging enough: "Well, if you're 84, then I think this is childish". (B2, female, 91 years, moderate dementia, small-scale living facility; game: Talking Tom)

"I think it's a nice invention, but what to do with it? [...] I don't prefer it, because it doesn't bring me anything. [...] The game is somewhat too low for me. [...] I think it is nice creation for people who can use it. I think it's particularly nice for older people who never come into contact with anything". (A10, male, 87 years, mild dementia, day-care centre; game: Shopping)

"It's a bit simple, with little variation. You tap somewhere and you will score or you won't. [...] It's not very exciting". (F3, male, 89 years, mild dementia, day-care centre; game: Soccer)

Moreover, the chosen game did not always meet the client's interest. A female participant at the day-care centre did not like playing Solitaire, because she considered this to be a male activity:

"This is no nice game. I think it's just a game for men". (A3, woman, 84 years, moderate dementia, day-care centre; game: Solitaire)

"This is more for younger people. I am very sorry for you. I wouldn't know. This isn't a thing for me". (F8, female, 81 years, moderately severe dementia, day-care centre; game: Talking Tom)

Sometimes, clients said not to be interested in playing games at all. They told that they were not a 'game person' and would rather do something else. "No, for now it is okay, but it doesn't excite me. I'd rather read a book". (F1, male, 85 years, moderate dementia, day-care centre; games: Checkerboard, Fishpond and iSjoel)

On some occasions, the clients had problems operating the touchscreen, which undermined a joyful playing session. One client who understood the purpose of the iSjoel game was not sure whether he wanted to play it again, because "It [pushing the puck] did not run smoothly" (F3, male, 89 years, moderate dementia, day-care centre; game: iSjoel).

Another client was very interested to play the Pets game, but had difficulty with tapping, resulting in no response to his touch:

"I liked the game, but it would be better if the pets responded if you touch them. [...] It was nice, but not again". (A6, male, 85 years, moderately severe dementia, day-care centre; game: Pets)

Sense of insecurity. Playing the iPad games could also lead to feelings of stress or insecurity. Sometimes the client did not understand the purpose of the game. Some clients thought that the game was a test, which made them nervous.

"I think there is nothing in it. I cannot do anything with it and it doesn't work like I want it to". (A9, male, 89 years, mild dementia, day-care centre; games: Soccer and iSjoel)

"I didn't fully understand it. I would if someone told me to do such and such". (B1, female, 83 years, moderate dementia, small-scale living facility; game: Checkers)

"Listen, to me it's all fake. It's all nice, but why grade it? It doesn't mean anything to me. Are you looking for people who are not fully sane?". (A10; did not play)

\section{Discussion AND CONCLUSIONS}

Our study is one of the first to explore the perspectives of people with dementia engaged in independent game-playing on a tablet. The results show that people with dementia can experience playing games on a tablet as a pleasant and meaningful activity.

\section{Positive experiences}

In the current study, positive experiences from playing games on a tablet comprised raised self-esteem, feelings of achievement, a sense of connection and belonging, identity, having something to do and admiration for the game. Three of the six psychological needs of people with dementia, as described by Kitwood ${ }^{20}$, are reflected in these positive experiences: identity, attachment and occupation. There are also similarities with the motives to engage in digital gaming of senior gamers, mostly without dementia, including pass time, challenge and enjoyment ${ }^{21}$.

In studies involving CIRCA, a hypermedia based conversation aid for older people with dementia, comparable positive and spontane- 
ous comments were expressed ${ }^{9}$. CIRCA, however, was designed to be a shared activity. "Living in the Moment" is a more recent project about making games for people with dementia to play independently. Comments on the digital video activities made by people with dementia in that study demonstrated enjoyment, engagement, autonomy and competence ${ }^{22}$.

Several studies explored the concept of meaningful activity for people with dementia. Phinney et $\mathrm{al}^{23}$ found that community-dwelling people living with dementia considered a wide range of activities, including leisure pastimes and household chores, as meaningful because these evoke feelings of pleasure and enjoyment, a sense of connection and belonging, and a sense of autonomy and personal identity. In another qualitative study, enjoyment and addressing an individual's psychological and social needs emerged as reasons for making an activity meaningful to residents in long-term care ${ }^{24}$.

It is difficult to assess the impact of involvement in meaningful activities on quality of life of people with dementia. An evidence-based review on the effect of interventions designed to establish, modify and maintain leisure, showed that there is little evidence for positive outcomes in quality of life for people with dementia, but increased activity engagement and caregiver satisfaction during visits are reported ${ }^{25}$. A more recent single study showed that people with dementia in residential aged care participating in household activities or other everyday activities have statistically significant higher quality of life ${ }^{26}$. Additionally, a recent case study found that mastering new technology, in this case a smartphone, had a positive impact on an individual's self-reported quality of life ${ }^{27}$. In a large study of 1144 residents with a dementia diagnosis in long-term care facilities, Smit et al. ${ }^{3}$ found that activity involvement was beneficial for the care relationship, positive affect, restlessness, social relations and having something to do.

Leng et al. ${ }^{28}$ compared iPad group activities with traditional activities, like cooking and craft work, in achieving well-being in a small quasiexperimental study including six persons with dementia attending a dementia day centre. They concluded that iPad group activity can be as effective and engaging as other activities.

\section{Negative experiences}

Negative experiences reported included failure (low self-esteem), annoyance and a sense of insecurity. In most cases, these negative experiences were the result of a mismatch between the selected game and the person with dementia's expectations, ambitions and interests. These clients were not 'in flow', that, according to Csikszentmihalyi's theory, is defined as "the subjective experience of engaging just-manageable challenges by tackling a series of goals, continuously processing feedback about progress, and adjusting action based on this feedback"29. Motivation to keep playing videogames also relies on a balance between challenge and success, with intermittent feelings of "anger, frustration, or sadness" experienced by players of all ages ${ }^{6}$. The clients with dementia who did not have a positive experience often qualified the games as 'boring' or 'childish'. Demonstrating that people living with dementia respond in similar ways to other game players is important for future development for games for this population.

Other negative experiences resulted through problems operating the touchscreen. Some clients found the touchscreen hard to operate. Specifically, they had difficulty with tapping, swiping or dragging as required by the apps. In other instances, the unexpected behaviour of the iPad or the app was confusing or frustrating to the person with dementia. In particular, pop-up ads could be annoying. These technical problems may undermine their sense of mastery.

Four characteristics that make multimedia leisure for people with dementia successful can be distinguished: an engaging, attractive and colourful interface; always obvious what to do next; an element of challenge and skill (a 'mastery' aspect); and continual feedback on the user's performance ${ }^{11,21}$. As the apps selected were not developed specifically for people with cognitive impairment, it is not surprising that these elements were not usually included.

\section{Strengths and weaknesses}

Many of the findings from this study are based on short interviews with people with dementia conducted shortly after having played a tablet game. Astell et al. ${ }^{22}$ also interviewed people with dementia at the end of each session to capture their immediate reactions to the sessions. In general, interviewing people with dementia offers very valuable and authentic data. In some instances, the participants' answers were socially suitable and polite. In that case, the observations provided additional information to that garnered through the post-game interviews. A participant, for example, could have qualified the game as nice, while hardly having played. On the other hand, some of the negative assessments of the game may have been based on the client's fear of exposing their deficits ${ }^{30}$.

We completed a large number of observations and feel that saturation of possible responses to 
game playing on a tablet has been reached, capturing both positive and negative experiences. Even though the study population was a selected sample of people with dementia who might have been potentially interested in digital gaming, this did not necessarily mean that they enjoyed the game playing. In the open population, however, attitudes may be more diverse than those reported in our study.

A weakness of our study was that playing the games was not completely carried out as a solo activity due to the study setting, as an observer was always present. Although most of the mentioned experiences relate to the game play itself, some of the positive feelings, frequently expressed as 'nice', may have resulted from the perceived interaction with the observer.

\section{Practical implications \\ Choice of games}

To prevent negative experiences of gaming, it is important that there is a match between the game, the touchscreen skills of the person with dementia, and their ambitions or interests. Our study adds to the growing body of evidence regarding the potential application of touchscreen technologies for people living with dementia ${ }^{31}$. A wide range of people with dementia can experience engagement and enjoyment of digital games, including those who have not used digital technologies before ${ }^{32}$. However, the potential of casual games on a tablet as a meaningful activity to people with dementia, depends on a number of factors, including the match between the game, the cognitive and touchscreen skills of the person with dementia, and their ambitions or interests. Therefore, care must be taken in introducing the games, identification of appropriate apps and provision of support. An early negative experience, for instance with an unsuitable app (lacking accessibility features to support people with cognitive impairment) can deter people from future efforts. A classification system of all touchscreen games and activities, combining game characteristics and player characteristics ${ }^{14}$, can be used in a, preferably interactive, decision aid to help choose a suitable game. Such a tool could start with an assessment of the touchscreen skills of the person with dementia, including their dexterity. Knowledge of their dexterity could then be combined with knowledge of the amount of different control methods in the available apps. This can guide decisions about whether any given app is suitable for that person with dementia.

Subsequently, the person with dementia can be asked which digital game they like to play. We need to think carefully about how games on a tablet are introduced and explained. Offering a choice from a number of familiar games may seem relatively easy, whereas it will be much more challenging to describe interactive animations or more abstract novel games to a person with dementia. Should, for example, Talking Tom be chosen because the client liked cats, or had good senses of humour? Familiarity alone, however, does not promote usability ${ }^{32}$. In our study, for example, the person with dementia could choose to play Shuffleboard because they like to play the real version of the game. However, digital versions may not be the same as the version of the game the person played before. Further guidance is needed on choosing the most suitable version of an app (where there are multiple versions). And where a game is usually played with more than one player, it should also be acceptable for solitary play.

Additionally, the amount of cognitive decline may play a role in choosing a game. LeBlanc et $\mathrm{al}^{33}$ found that assessment of activities that a person with dementia may find enjoyable, using the Pleasant Events Schedule, better predicted subsequent engagement in persons with dementia with MMSE $\geq 10$ than in persons with dementia with MMSE < 10. In the current study, it was observed that as a result of disengagement, more games were tried per session in cases of people with severe dementia.

\section{App design}

Participants were frequently able to play the games independently ${ }^{34}$. However, they often needed help with starting the game, repeated prompting to continue playing or help to solve problems, e.g., navigating unexpected menus that might pop-up. Alm et al. ${ }^{9}$ also found that the explorable virtual environments did not work as a single unsupported activity, as they did not give enough structure to keep the people with dementia engaged. Furthermore, evidence suggests that some digital video games do not contain sufficient purpose or challenge to maintain the participant's interest, and, after completion, do not invite repetition ${ }^{22}$. To promote prolonged and independent game play by people with dementia, some fundamental conditions should be met. Alm et al. ${ }^{9}$ paid attention to an engaging and attractive interface and easy and pleasurable navigation. Further experimentation is necessary on how best to deploy the timing of the appearance of text boxes or voice prompts ${ }^{12}$. In our study, text boxes and auditory cues were integrated in the three new game prototypes. The pet and shopping app, however, were often considered too childish and did not challenge the participant's interest. 


\section{Dementia and gaming}

\section{Future implementation}

This study has confirmed that people with dementia are willing to accept the tablet and experience casual gaming on a tablet as a pleasant and meaningful activity. Previous research ${ }^{23}$ has found that professional caregivers are positive about gaming on a tablet by their clients as well. They see casual gaming as an addition to the traditional activities in long-term care that may not be sufficiently challenging or engaging for some clients or for those who do not wish to participate within a group. An interactive tool to support the choice of the game that is most suitable and a database of dementiafriendly games may support the use of gaming on a tablet by people with dementia, in health care organisations as well as at home. To address this, the ActoDementia framework and website have been developed to provide guidance and suggestions for selecting apps that are suitable for people with cognitive impairment ${ }^{35}$.

While the focus of our study was to investigate the use the potential of gaming on a tablet as a meaningful and pleasant individual activity, another learning point is that the digital activities can be the basis of social interaction between people with dementia and their caregivers or potentially family visitors. As such, the tablet can be used for a broad range of activities in dementia care.

\section{References}

1. Logsdon RG, McCurry SM, Teri L. Evidence-based interventions to improve quality of life for individuals with dementia. Alzheimers Care Today 2007; 8(4):309-318

2. Castro-Monteiro E, Alhayek-Aí M, Diaz-Redondo A, Ayala A, Rodriquez-Blazquez C, Rojo-Perez F, Martinez-Martin P, Forjaz MJ. Quality of life of institutionalized older adults by dementia severity. International Psychogeriatrics 2016;28(1):83-92; doi:10.1017/S1041610215000757

3. Smit D, de Lange J, Willemse B, Twisk J, Pot AM. Activity involvement and quality of life of people at different stages of dementia in long term care facilities. Aging \& Mental Health 2015;20(1):100-109; do i:10.1080/13607863.2015.1049116

4. NICE [National Institute for Health and Care Excellence]. Dementia: independence and wellbeing. NICE quality standard 30. Manchester: NICE; 2013; http://www.nice.org.uk/guidance/qs30; retrieved March 23, 2017

5. Rotterdam University. InTouch... Touch screen toepassingen / happy games voor mensen met dementie [Touch screen applications / happy games for people with dementia]. Rotterdam: Rotterdam University of Applied Sciences; 2011

6. Granic I, Lobel A, Engels RCME. The benefits of playing video games. American Psychologist 2014;69(1):66-78; doi:10.1037/a0034857

7. Joddrell P, Astell AJ. The use of touchscreen technology with people living with dementia: A review of the literature. JMIR Rehabilitation and Assistive Technologies (JRAT) 2016;3(6):e10

8. Alm N, Astell A, Ellis M, Dye R, Gowans G, Campbell J. A cognitive prosthesis and communication support for people with dementia. Neuropsychological Rehabilitation 2004;14(1-2):117-134; doi:10.1080/09602010343000147

9. Alm N, Dye R, Gowans G, Campbell J, Astell A, Ellis M. A communication support system for older people with dementia. Computer 2007;40(5):35-41; doi:10.1109/mc.2007.153

10. Astell AJ, Ellis MP, Bernardi L, Alm N, Dye R, Gowans G, Campbell J. Using a touch screen computer to support relationships between people with dementia and caregivers. Interacting

with Computers 2010;22(4):267-275; doi:10.1016/j. intcom.2010.03.003

11. Alm N, Astell A, Gowans G, Dye R, Ellis M, Vaughan P, Riley P. Engaging multimedia leisure for people with dementia. Gerontechnology 2009;8(4):236246; doi:10.4017/gt.2009.08.04.006.00

12. Alm N, Astell A, Gowans G, Dye R, Ellis M, Vaughan P, Riley P. Lessons learned from developing cognitive support for communication, entertainment, and creativity for older people with dementia. Lecture Notes in Computer Science 2009(5614):195201; doi:10.1007/978-3-642-02707-9_21

13. Cordia AL. Design of an iPad cover for people with cognitive impairment. Gerontechnology 2015;13(4):426427; doi:10.4017/gt.2015.13.4.010.00

14. Cordia AL. Randvoorwaarden ontwerp happy games voor ouderen met dementie [Precondition designed happy games for elderly people with dementia]. Rotterdam: Hogeschool Rotterdam, Kenniscentrum Zorginnovatie; 2014

15. Haan R de, Limburg M, Schuling J, Broeshart J, Jonkers L, Zuylen P van. Klinimetrische evaluatie van de Barthel-index, een maat voor beperkingen in het dagelijks functioneren [Clinimetric evaluation of the Barthel Index, a measure of limitations in daily activities]. Nederlands Tijdschrift voor Geneeskunde 1993;137(18):917-921

16. Zorginstituut Nederland. Middelen bij dementie. [Dementia medications]; https://www.farmacotherapeutischkompas.nl/bladeren-volgens-boek/inleidingen/inl-middelen-bij-dementie. Retrieved November 16, 2012

17. Folstein MF, Folstein SE, McHugh PR. "Mini-mental state". A practical method for grading the cognitive state of patients for the clinician. Journal of Psychiatric Research 1975;12(3):189-198; doi:10.1016/00223956(75)90026-6

18. Boeije H. Analyseren in kwalitatief onderzoek. [Analysis in qualitative research]. Den Haag: Boom Lemma Uitgevers; 2005

19. Boersma F, Hertogh CM, Olde Rikkert MG. Gedragscode voor de beoordeling van verzet bij wetenschappelijk onderzoek met wilsonbekwame (psycho) geriatrische patiënten. [Ethical code for evaluation of unwillingness in scientific research legally incompetent (psycho) geriatric patients]. Tijdschrift voor Gerontologie en Geriatrie 1999;30(6):244-246 


\section{Dementia and gaming}

20. Kitwood T. Dementia reconsidered. The person comes first. Philadelphia: Open University Press 1997;12(6):32; doi:10.7748/ns.12.6.32.s44

21. Nap HH,De Kort YAW, IJsselsteijn WA. Senior gamers: Preferences, motivations and needs. Gerontechnology 2009;8(4):247-262; doi:10.4017/ gt.2009.08.04.003.00

22. Astell A, Alm N, Dye R, Gowans G, Vaughan P, Ellis M. Digital video games for older adults with cognitive impairment. Lecture Notes in Computer Science 2014;8547; 264-271; doi:10.1007/978-3319-08596-8_42

23. Phinney $\mathrm{A}$, Chaudhury $\mathrm{H}, \mathrm{O}^{\prime}$ Connor DL. Doing as much as I can do: The meaning of activity for people with dementia. Aging \& Mental Health 2007;11(4):384393; doi: 10.1080/13607860601086470

24. Harmer BJ, Orrell M. What is meaningful activity for people with dementia living in care homes? A comparison of the views of older people with dementia, staff and family carers. Aging \& Mental Health 2008;12(5):548-558; doi:10.1080/13607860802343019

25. Letts L, Edwards M, Berenyi J, Moros K, O'Neill C, O'Toole C, McGratch C. Using occupations to improve quality of life, health and wellness, and client and caregiver satisfaction for people with Alzheimer's disease and related dementias. The American Journal of Occupational Therapy 2011;65(5):497504; doi:10.5014/ajot.2011.002584

26. Edvardsson D, Petersson L, Sjogren K, Lindkvist M, Sandman PO. Everyday activities for people with dementia in residential aged care: Associations with person-centredness and quality of life. International Journal of Older People Nursing 2013;9(4):269-276; doi:10.1111/opn.12030

27. Astell AJ, Malone B, Williams G, Hwang F, Ellis MP. Leveraging everyday technology for people living with dementia: A case study. Journal of Assistive Technology 2014;8(4):164-176; doi:10.1108/jat-01-
2014-0004

28. Leng FY, Yeo D, George S, Barr C. Comparison of iPad applications with traditional activities using personcentred care approach: Impact on well-being for persons with dementia. Dementia 201313(2):265273; doi:10.1177/1471301213494514

29. Nakamura J, Csikszentmihalyi M. The concept of flow. In: Csikszentmihalyi M, editor. Flow and the foundations of positive psychology, Netherlands, Springer 2014; pp 239-263; doi:10.1007/978-94017-9088-8_16

30. Weisman, S. Computer games for the frail elderly. Gerontologist 1983;23(4):361-363; doi:10.1093/geront/23.4.361

31. Joddrell P, Astell AJ. Studies involving people with dementia and touchscreen technology: A literature review. JMIR Rehabilitation and Assistive Technologies 2016;3(2):e10; doi:10.2196/rehab.5788

32. Astell AJ, Joddrell P, Groenewoud H, de Lange J, Goumans M, Cordia A, Schikhof Y. Does familiarity affect the enjoyment of touchscreen games for people with dementia? International Journal of Medical Informatics 2016;91:e1-e8; doi:10.1016/j. ijmedinf.2016.02.001

33. LeBlanc LA, Raetz PB, Baker JC, Strobel MJ, Feeney BJ. Assessing preference in elders with dementia using multimedia and verbal Pleasant Events Schedule. Behavioral Interventions 2008;23(4):213-225; doi:10.1002/bin.266

34. Groenewoud JH, Lange J de. Evaluatie van individuele happy games op de iPad voor mensen met dementie. Rotterdam: Research Centre Innovations in Care; 2014

35. Joddrell P, Hernandez A, Astell AJ. Identifying existing, accessible touchscreen games for people with dementia. Lecture Notes in Computer Science 2016;9758:509-514; doi:10.1007/978-3-319-412641_69 